\title{
A TEMPORALIDADE DO PRETÉRITO IMPERFEITO DO SUBJUNTIVO EM RELAÇÃO A SEU PONTO DE REFERÊNCIA: PERSPECTIVAS TEÓRICAS
}

\author{
Angela Cristina Di Palma Back ${ }^{\star}$ \\ Universidade do Extremo Sul Catarinense \\ Criciúma, SC, Brasil
}

Márluce Coan (UFC - CNPq) ${ }^{* *}$

Universidade Federal do Ceará

Centro de Humanidades

Departamento de Letras Vernáculas

Fortaleza, CE, Brasil

\begin{abstract}
Resumo: Neste artigo, as perspectivas de Bello (1841), Reichenbach (1947), Comrie (1990) e Rojo e Veiga (1999) sobre ponto de referência são aplicadas a 350 dados de pretérito imperfeito do subjuntivo, provenientes de 60 entrevistas sociolinguísticas do Atlas Sociolinguístico da região da AMREC. O propósito é: demonstrar em que medida tais perspectivas se aproximam ou se distanciam; comprovar empiricamente a aplicação das propostas, mediante análise quali-quantitativa; e atestar que tempo é uma categoria discursiva. Para isso, observa similaridades acerca de: poder explanatório; recursos lógicos e correlação entre tempo cronológico e gramatical. A principal diferença reside na visão da temporalidade: lógica ou discursiva. Quanto aos dados, 116 são ambíguos, na perspectiva lógica de Bello (1841), Reichenbach (1947) e Comrie (1990). Na proposta de Rojo e Veiga (1999), por ser recursiva e ultrapassar os limites da frase, a ambiguidade se desfaz: os dados são discursivamente interpretados como anteriores ou posteriores ou cotemporais ao ponto de referência.
\end{abstract}

Palavras-chave: Tempo gramatical. Tempo discursivo. Ambiguidade. Cotemporalidade.

1 INTRODUÇÃO

Neste artigo, comparam-se as perspectivas de Bello (1841), Reichenbach (1947), Comrie (1990) e Rojo e Veiga (1999) sobre ponto de referência, especificamente, para análise de dados do pretérito imperfeito do subjuntivo (doravante PIS). Os dados utilizados para a discussão são provenientes de 60 entrevistas sociolinguísticas do banco Atlas Sociolinguístico da região da AMREC (BACK, 2008). Embora se trate de estudo

\footnotetext{
* Doutora em Linguística pela Universidade Federal de Santa Catarina. Professora do Programa de PósGraduação em Educação da UNESC. Coordenadora do Grupo de Pesquisas LITTERA - Correlações entre cultura, processamento e ensino: a linguagem em foco. Email: acb@unesc.net

** Doutora em Linguística pela Universidade Federal de Santa Catarina. Professora do Programa de PósGraduação em Linguística da UFC. Coordenadora do Grupo de Pesquisas Sociolinguísticas - SOCIOLINCE. Email: coanmalu@ufc.br
} 
quantitativo, já que os 350 dados são mapeados de acordo com as perspectivas dos autores supracitados, escolhemos apenas três dados para ilustrar a aplicação das propostas. Em cada uma das quatro seções, apresentamos a proposta de um autor e, na sequência, são analisados os mesmos três dados com o propósito principal de, nas considerações finais do artigo, demonstrar em que medida tais perspectivas se aproximam ou se distanciam. Dos três dados, dois demonstram as perspectivas lógico-temporais em que o PIS ou é cotemporal ou anterior a seu ponto de referência. O terceiro dado ilustra os casos ambíguos encontrados na amostra, requerendo, portanto, alargamento da frase ao discurso. A priori, não tínhamos a intenção de escolher esta ou aquela proposta, apenas demonstrar uma correlação entre teorias e prática de análise, mas uma parcela significativa dos dados (116 de 350) requer direcionamento discursivo para a interpretação da temporalidade do PIS.

\section{A TEMPORALIDADE DO PRETÉRITO IMPERFEITO DO SUBJUNTIVO EM RELAÇÃO A SEU PONTO DE REFERÊNCIA: A PERSPECTIVA DE BELLO (1841)}

Para Bello (1841), a referência para as situações não é o "acto de la palabra", metalinguagem que se correlaciona à denominação reichenbachiana - ponto de fala (point of speech), conforme veremos na seção três. Bello, em se tratando do pretérito imperfeito, aciona como ponto de referência (PR) outra situação pretérita, e não mais o momento de fala, situação essa pretérita e simultânea ao imperfeito. A fórmula do autor para essa situação é CA - copretérito $^{1}$, porque a situação no imperfeito e outra situação coexistem no passado.

As indicações de anterioridade, simultaneidade e posterioridade ao tempo de fala evidenciam três tempos verbais: passado, presente e futuro, respectivamente. Esses três momentos são nomeados como anterioridade (A), coexistência $(C)$ e posterioridade $(\mathrm{P})$ ao momento de fala (PR universal), tomados para representar relações temporais simples e complexas, como esboça o quadro a seguir (BELLO, 1979 [1841]; 1984 [1847]). O conceito de Tempo complexo, em Bello, nada tem a ver com a forma do verbo ser simples ou composta, mas com Tempo absoluto e relativo (noções estas presentes na proposta de Comrie, 1990, conforme veremos na seção quatro). Os Tempos absolutos têm o momento de fala, coexistência (C), como ponto de referência, a exemplo de passado (A) e futuro (P), ou seja, o tempo verbal absoluto é aquele que inclui como parte de seu significado o momento presente como PR; já para se interpretar os Tempos verbais relativos, há de se levar em consideração não só o momento presente como também outro ponto no Tempo, dado pelo contexto como ponto de referência.

\footnotetext{
${ }^{1}$ Copretérito equivale ao pretérito imperfeito dos modos indicativo e subjuntivo em Português.
} 
Quadro 1 - Relações temporais simples e complexas

\begin{tabular}{|l|l|l|l|}
\hline Relações de tempo & Coexistência & Anterioridade & Posterioridade \\
\hline Simples & Presente (C) & Passado (A) & Futuro (P) \\
\hline Complexa & Copretérito (CA) & & Pós-pretérito (PA) ${ }^{2}$ \\
\hline
\end{tabular}

Fonte: Bello (1979 [1841]; 1984 [1847]).

Das relações acima, nas que o autor chama de complexas, observamos, por meio do acréscimo de $(\mathrm{A})$ - traço de anterioridade - à notação, que o PR não é o momento da fala, mas outro tempo no passado, de modo que CA, por exemplo, corresponde a um presente do passado, ou seja, há coexistência de dois tempos no passado, a exemplo da coexistência do presente (C) com o momento de fala. Às relações apontadas no quadro acima, somase o traço de anterioridade (A), quando a língua expressa o tempo por meio de formas compostas, resultando novas fórmulas como: o antepresente (AC) e o antecopretérito (ACA) no eixo da coexistência; o antepassado (AA), no eixo da anterioridade, e, por fim, o antefuturo (AP) e ante-pós-pretérito (APA) no eixo da posterioridade.

Dos 350 dados analisados, 158 representam cotemporalidade, dos quais 109 são CA, como ilustra a tabela 1 abaixo. Embora seja um número expressivo, nem sempre há cotemporalidade em cena, conforme veremos na sequência da análise. A expressividade desse uso leva-nos a uma primeira constatação: o PIS tem como PR, primordialmente, uma situação passada a ele cotemporal, relação representada pelo esquema [MS,MR---$\mathrm{MF}$. Eis o que ilustram exemplo e diagrama 01: situação cotemporal a outra no passado, funcionando como uma espécie de presente do passado.

Tabela 1 - Temporalidade do PIS, conforme Bello (1979 [1841]; 1984 [1847])

\begin{tabular}{llr}
\hline Esquemas temporais & & Ocorrências \\
\hline \multirow{2}{*}{ Cotemporalidade } & MS, MR -----MF - CA & 109 \\
& MS, MR, MF & 18 \\
& MF------MR, MS & 31 \\
Posterioridade & MR ----MS ----MF - PA & 37 \\
& MR ----MF ----MS & 6 \\
Outros $^{3}$ & MR,MF ------MS & 21 \\
\hline TOTAL & & 128 \\
\hline
\end{tabular}

Fonte: Elaboração própria

(01) Geralmente em quatro, cinco, né? Nunca sozinho, porque a gente ia pra longe, né? Ia pra $\varnothing$ tudo ao redor, né? E era difícil alguém que TIVESSE um carro naquela época. *Era mais ou menos isso. (SC CRI 03, p. 005)

\footnotetext{
${ }^{2} \mathrm{~A}$ interpretação do pós-pretérito equivale à do futuro do pretérito do indicativo e também é percebida em contextos do pretérito imperfeito do subjuntivo.

${ }^{3}$ Estamos aqui nos referindo a 'outros' como esquemas temporais ligados à anterioridade.

4 As ocorrências tentam trabalhar com a sintaxe real da fala dos informants, considerando todas as hesitações e interrupções.
}

BACK, Angela Cristina Di Palma; COAN, Márluce. A temporalidade do pretérito imperfeito do subjuntivo em relação a seu ponto de referência: perspectivas teóricas. Linguagem em (Dis)curso - LemD, Tubarão, SC, v. 18, n. 2, p. 375-391, maio/ago. 2018. 
Diagrama 01 - Expressão modo-temporal do PIS como copretérito - CA

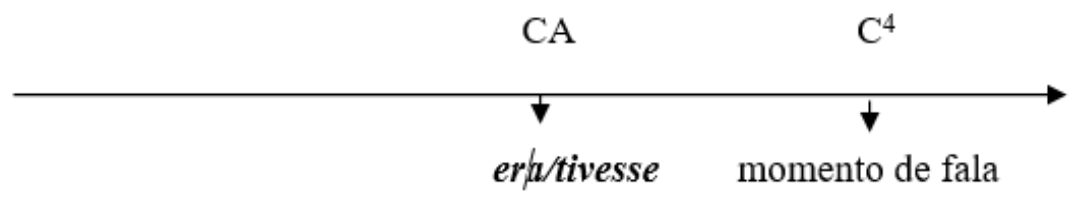

A ocorrência a seguir ilustra um caso de PIS como PA (pós-pretérito): função temporal de futuro do passado, ou seja, o PR (era obrigado a fazer) é passado e o PIS (encostasse) é futuro a essa referência. Não se vê cotemporalidade nessa cena, ou seja, enquanto se está fazendo a taipa, esta não encosta no telhado; terminou-se a taipa, então, deve encostar no telhado. Assim, PA esboça um valor temporal de uma situação que é posterior a outra no passado (pós-pretérito), fórmula também prevista por Bello para o sse do castelhano. Em nossos dados, foram 37 casos de PA, o que equivale a 15,71\% da amostra.

(02) Quando a gente, de vez em quando escutava, calcava o peso lá pra trá0s e (inint) acarcava e fazia aquela 0 quebraçada ("pra dizer") que nó0s faziamos uma taipa, que era obrigado a fazer uma taipa que ENCOSTASSE até no teto, uma taipa de pedra, [da]- da própria frente, né?* Então encostava até assim no teto, só deixava um corredor pelo meio, né? (SCCRI01, p. 5)

Diagrama 02 - Expressão modo-temporal do PIS como pós-pretérito - PA

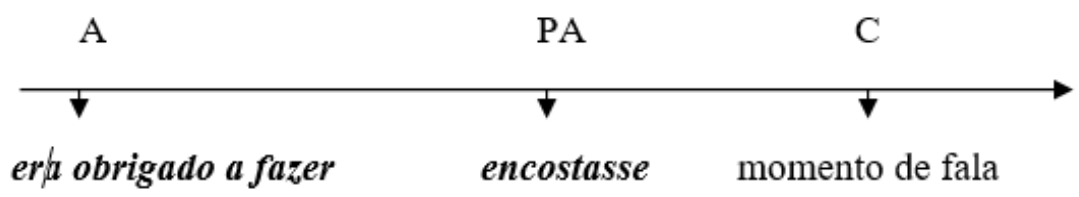

Bello verifica que algumas formas assumem valores temporais primários, secundários e valores metafóricos que, não necessariamente, focalizam o tempo. $\mathrm{O}$ autor assume que, para cada forma verbal, há um 'valor fundamental' que se associa ao tempo primário; outras expressões que dele (tempo primário/primitivo) derivam, passam a exprimir valores secundários: situações codificadas pelo infinitivo, por exemplo, não esboçam relação temporal determinada com o instante em que a proferimos, portanto sua temporalidade deve ser inferida do contexto; é o que ocorre com fazer, do exemplo (02), que tem acepção de passado por ser um tempo relativo atrelado ao pretérito (era obrigado).

Para além dos dois valores claramente verificados nos dados: 109 de CA e 37 de PA, há casos em que três interpretações são possíveis, se aplicada a proposta de Bello. Vejamos:

(03) Meu pai não queria que nós NAMORÁSSEMOS [...](SCCRI01, p. 8)

Em se tratando especificamente do queria, atribuiremos a essa forma o valor temporal de A que é o PR para namorássemos. Nessas circunstâncias, namorássemos 
seria posterior à situação queria, expressando-se como futuro do passado, na terminologia de Bello - PA (pós-pretérito), conforme representação em (03), ou, dada a ambiguidade, namorássemos coloca-se na linha do tempo como anterior à situação codificada por queria, produzindo a interpretação retratada em (04). É possível, ainda, a interpretação do imperfeito do subjuntivo, namorássemos como CA, ou seja, cotemporal à situação expressa por queria, conforme representação em (05).

Diagrama 03 - Expressão modo-temporal do PIS como PA - pós-pretérito

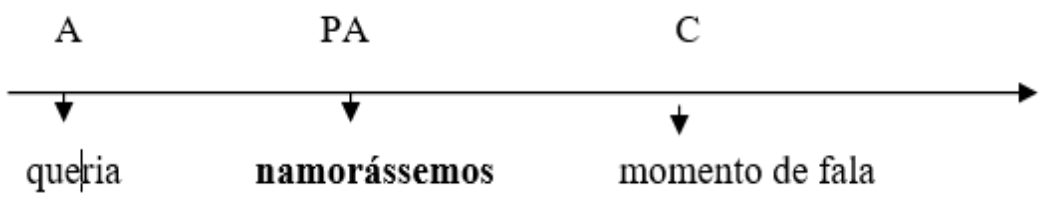

(PR)

Diagrama 04 - Expressão modo-temporal do PIS como AA - antepretérito|

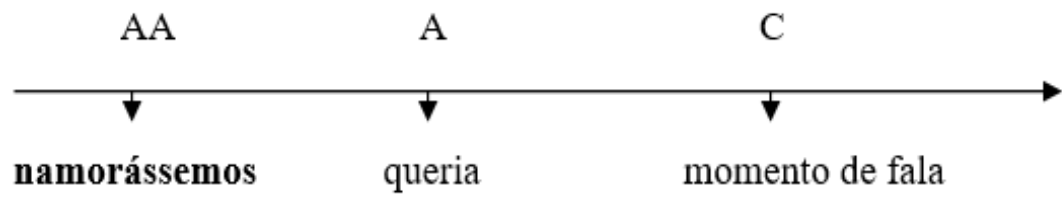

(PR)

Diagrama 05 - Expressão modo-temporal do PIS como CA - copretérito

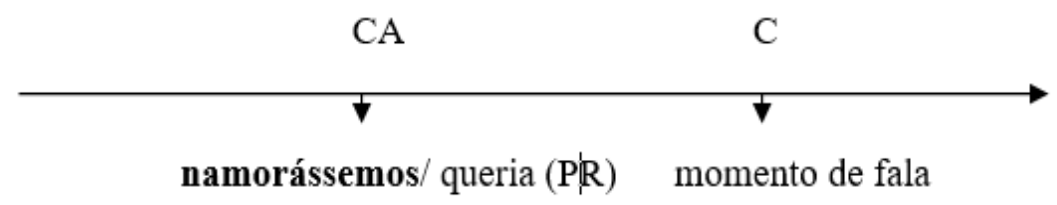

Conforme verificamos, nas representações acima, nem sempre o imperfeito do subjuntivo é uma situação passada cotemporal a outra situação passada; pode codificar anterioridade ou posterioridade, do que decorre maior complexidade em sua representação temporal e comprovação de que uma forma serve a mais funções, ou seja, em virtude dos processos de gramaticalização, nem sempre há correlação de um-para-um entre forma e função.

Geralmente, gramaticalização refere-se ao desenvolvimento de morfemas gramaticais a partir de lexicais, mas há autores que citam outros mecanismos: a) conforme Bybee, Perkins e Pagliuca (1994), extensão metafórica (extensão entre domínios), inferência (o falante implica mais do que ele diz e o ouvinte infere mais do que foi dito), generalização (perda de traços específicos do significado - redução semântica - com consequente expansão), harmonia (usos similares, por exemplo, usos modais na oração principal e na subordinada) e absorção (retenção de um traço gramatical); b) segundo Givón (1979), reanálise de padrões discursivos em gramaticais e de funções discursivas em funções semânticas sentenciais e c) de acordo com Heine et al. (1991), mudanças de 
ordem semântico-pragmática (de significados baseados na situação externa - espacial para significados baseados na situação interna - perceptual/cognitiva, de significados baseados em situação externa ou interna para significados baseados em função textual coesão textual e tendência a significados tornarem-se progressivamente situados nas crenças do falante). Neste caso específico do PIS em relação ao ponto de referência, parece que estamos diante de um caso de especialização por generalização. Vejamos isso, inicialmente, via tabela 2:

Tabela 2 - Funções temporais do PIS no corpus

\begin{tabular}{lrr}
\hline Tempo & Frequência & Percentual \\
\hline Copretérito & 109 & 31,14 \\
Pós-pretérito $^{5}$ & 37 & 10,57 \\
Futuro 3 $^{5}$ & 31 & 8,86 \\
Futuro 1 & 06 & 1,71 \\
Futuro 2 & 21 & 6,00 \\
Presente 1 $^{6}$ & 11 & 3,14 \\
Presente 2 & 07 & 2,00 \\
Antefuturo & 04 & 1,14 \\
Antepretérito & 08 & 2,29 \\
Inconclusos & 116 & 33,15 \\
\hline TOTAL & 350 & 100,00 \\
\hline
\end{tabular}

Dos 350 dados analisados, como podemos visualizar acima, considerando apenas o eixo do pretérito, há 109 de copretérito, 08 de antepretérito, 37 de pós-pretérito e 116 ambíguos. A priori, a função copretérita, sincronicamente, parece ser a função primária do PIS, mas a forma que se especializa, para codificar uma situação eventual, generalizase para três temporalidades: passado em relação ao PR, cotemporalidade ao PR e futuro ao PR.

Do exposto, verifica-se que a temporalidade do PIS em relação ao seu PR é corretamente identificada em 234 dados dos 350, o que confere à proposta de Bello aplicabilidade à maioria dos casos, excluindo-se os ambíguos (116 dados da amostra), pois estes necessitam de análise discursiva e não apenas lógico-temporal. Seguindo o percurso proposto no início do artigo, veremos, agora, a proposta de Reichenbach aplicada aos mesmos dados.

\footnotetext{
${ }^{5}$ A interpretação do futuro coloca em perspectiva uma escala de temporalidade, a partir de sua correlação com o ponto de referência: 1) [MR-MF-MS], 2) [MR,MF - MS], e 3) [MF - MR,MS]. Esse modo escalar de compreender o tempo futuro ilustra a natureza não discreta das funções.

${ }^{6}$ A exemplo do dito na nota 4 , o presente também nos possibilitou duas interpretações, uma das quais exibe o aspecto durativo: 1) [MR,MF,MS] e 2) [MR------------MR,MF,MS]. 


\section{A TEMPORALIDADE DO PRETÉRITO IMPERFEITO DO SUBJUNTIVO EM RELAÇÃO A SEU PONTO DE REFERÊNCIA: A PERSPECTIVA DE REICHENBACH (1947)}

Para explicar a relação entre o conceito de tempo e sua expressão gramatical, fazse, na maioria dos estudos, referência à formalização proposta por Reichenbach (1947). Segundo Corôa (2005), o autor, em função de sua experiência no ensino, tanto de lógica quanto de línguas estrangeiras, foi o primeiro lógico a formalizar uma interpretação temporal das línguas naturais, levando em consideração três pontos teóricos na linha do tempo: event $(E)$ - momento do evento, reference $(R)$ - ponto de referência e speech $(S)$ - momento de fala, o que permite ao analista representar o tempo tridimensionalmente. Reichenbach esquematiza nove fórmulas fundamentais (conforme quadro 2), destacando que a totalidade de suas combinações nunca ocorre em uma língua natural, em função de que, conforme Corôa (2005), as reais combinações de cada língua desenvolvem-se historicamente, embora mantenham relações lógicas com essa tripartição de pontos. No cálculo utilizado por Reichenbach, em se tratando da expressão de passado, presente e futuro, a referência (R) é relativa ao momento de fala (S). Já a posição do evento, em relação à referência, é indicada por meio das noções de anterioridade temporal, simultaneidade e posterioridade.

\section{Quadro 2 - Fórmulas fundamentais para os tempos verbais}

\begin{tabular}{|l|l|l|l|}
\hline No. & Structure & New Name & Traditional Name \\
\hline 01 & E-R $-\mathrm{S}^{7}$ & Anterior past & Past perfect \\
\hline 02 & $\mathrm{E}, \mathrm{R}-\mathrm{S}$ & Simple past & Simple past \\
\hline \multirow{3}{*}{03} & $\mathrm{R}-\mathrm{E}-\mathrm{S}$ & Posterior past & \\
\cline { 2 - 3 } & $\mathrm{R}-\mathrm{S}, \mathrm{E}$ & -- \\
\cline { 2 - 3 } & $\mathrm{R}-\mathrm{S}-\mathrm{E}$ & Anterior Past & Present perfect \\
\hline \multirow{2}{*}{04} & $\mathrm{E}-\mathrm{S}, \mathrm{R}$ & Simple present & Present \\
\hline 05 & $\mathrm{~S}, \mathrm{R}, \mathrm{E}$ & Posterior present & Simple future \\
\hline 06 & $\mathrm{~S}, \mathrm{R}-\mathrm{E}$ & & \\
\hline \multirow{3}{*}{07} & $\mathrm{~S}-\mathrm{E}-\mathrm{R}$ & Anterior future & Future perfect \\
\cline { 2 - 3 } & $\mathrm{S}, \mathrm{E}-\mathrm{R}$ & & \\
\cline { 2 - 3 } & $\mathrm{E}-\mathrm{S}-\mathrm{R}$ & Simple future & Simple future \\
\hline 08 & $\mathrm{~S}-\mathrm{R}, \mathrm{E}$ & Posterior future & -- \\
\hline 09 & $\mathrm{~S}-\mathrm{R}-\mathrm{E}$ & & \\
\hline
\end{tabular}

Fonte: Reichenbach (1947, p. 297).

Embora Reichenbach não aborde o imperfeito do subjuntivo, sua constituição temporal pode ser depreendida dos diagramas que o autor propõe. Exatamente como em Bello, verificamos dois usos recorrentes nos dados: um que envolve cotemporalidade

\footnotetext{
${ }^{7} \mathrm{O}$ passado anterior codifica um evento anterior à referência que, por sua vez, é anterior ao momento de fala. Quando há vírgulas, a leitura é de simultaneidade, por exemplo, em E, R-S, evento e referência são simultâneos, mas anteriores ao momento da fala.
} 
entre evento e referência (158 dados) e outro que mostra posterioridade do PIS em relação à referência (64 dados), usos que se encaixam, respectivamente, nos esquemas de passado simples e passado anterior. Escolhemos, como na seção anterior, os mesmos exemplos para ilustração, assim a comparação pode ser mais evidente. O diagrama 06 apresenta era como ponto de referência para tivesse, demonstrando uma relação de cotemporalidade entre ambas as situações. Já o diagrama 07 ilustra era obrigado como situação anterior a encostasse. As análises são iguais às de Bello (1979 [1841]; 1984 [1847]), já que a situação no imperfeito se apresenta cotemporalmente ou posteriormente ao PR, embora sejam anteriores ao momento de fala.

(01) Geralmente em quatro, cinco, né? Nunca sozinho, porque a gente ia pra longe, né? Ia pra $\varnothing$ tudo ao redor, né? E era difícil alguém que TIVESSE um carro naquela época. *Era mais ou menos isso. (SC CRI 03, p. 005)

Diagrama 06 - Expressão modo-temporal do PIS como presente do passado

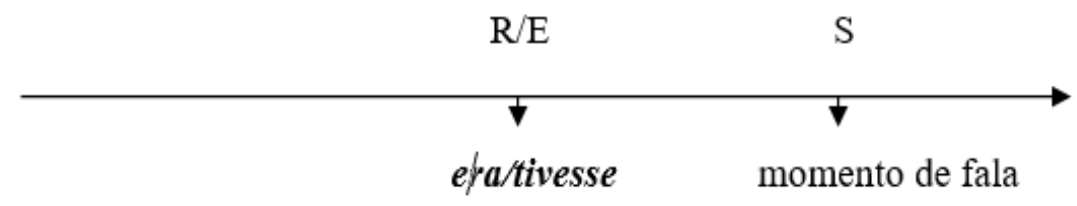

(02) Quando a gente, de vez em quando escutava, calcava o peso lá pra trá0s e (inint) acarcava e fazia aquela 0 quebraçada ("pra dizer") que nó0s faziamos uma taipa, que era obrigado a fazer uma taipa que ENCOSTASSE até no teto, uma taipa de pedra, [da]- da própria frente, né?* Então encostava até assim no teto, só deixava um corredor pelo meio, né? (SCCRI01, p. 5)

Diagrama 07 - Expressão modo-temporal do PIS como futuro do passado

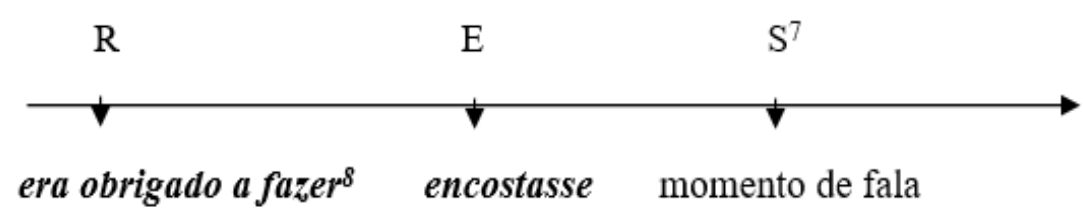

(03) Meu pai não queria que nós NAMORÁSSEMOS [...](SCCRI01, p. 8)

Com relação ao dado (03), acima, a exemplo da análise anterior, tomaremos queria (imperfeito) como PR para namorássemos, e o momento de fala como PR para queria. Contudo, há indeterminação da localização de queria em relação a namorássemos ou vice-versa, de modo que não se pode afirmar, sem o auxílio de outras pistas, se namorássemos é anterior, cotemporal ou posterior a queria. A diagramação que segue é idêntica à apresentada acima, a partir da proposta de Bello. Mudam-se apenas as denominações: em vez de copretérito, pós-pretérito e antepretérito, há E (event) momento do evento; $\mathrm{R}$ (reference) - ponto de referência e S (speech) - momento de fala. 
Diagrama 08 - Expressão modo-temporal do PIS como futuro do passado

\begin{tabular}{ccc}
\hline & $\downarrow$ & $\downarrow$ \\
$\mathrm{R}$ & $\mathrm{E}$ & $\mathrm{S}$ \\
queria & namorássemos & momento de fala \\
Ou & &
\end{tabular}

Diagrama 09 - Expressão modo-temporal do PIS como passado do passado

\begin{tabular}{ccc}
\hline$\downarrow$ & $\downarrow$ & $\downarrow$ \\
$\mathrm{E}$ & $\mathrm{R}$ & $\mathrm{S}$ \\
namorássemos & queria & momento de fala
\end{tabular}

$\mathrm{ou}$

Diagrama 10 - Expressão modo-temporal do PIS como cotemporalidade|pretérita

\begin{tabular}{cc}
\hline & $\checkmark$ \\
E,R & $S$ \\
queria & momento de fala \\
namorássemos &
\end{tabular}

A primeira análise encerra uma interpretação de que o casal ainda não namorava e o pai, de antemão, já observando o que poderia vir a ser, não queria; a segunda interpretação pressupõe a situação de que o casal já namorava e o pai, ao saber disso, pôsse contra; a terceira possibilidade de interpretação do dado acima é de cotemporalidade entre queria e namorássemos. Em nossos dados, são 116 casos dessa natureza, cuja localização é ambígua; isso porque ambas têm viés lógico-temporal. Aplicando a perspectiva de Bello ou de Reichenbach, chegamos aos mesmos resultados: o imperfeito pode ser cotemporal, posterior ou anterior a seu ponto de referência; no entanto, há dados ambíguos, os quais não podem ser interpretados exclusivamente pela perspectiva lógica, requerendo ampliação do nível de análise da frase ao texto/discurso. Segue-se a essas análises a proposta de Comrie (1990), cuja configuração é similar: embora as denominações mudem, as relações temporais continuam consideradas em nível frasal.

\section{A TEMPORALIDADE DO PRETÉRITO IMPERFEITO DO SUBJUNTIVO EM RELAÇÃO A SEU PONTO DE REFERÊNCIA: A PERSPECTIVA DE COMRIE (1990)}

Seguindo na direção proposta por Reichenbach (1947), Comrie (1990) estabelece o momento de fala como centro dêitico; assim, três tempos verbais básicos formam a espinha dorsal da referência temporal: presente, passado e futuro, chamados de tempos verbais absolutos em oposição aos relativos e relativo-absolutos. 
Os absolutos têm o momento de fala como ponto de referência, mas é possível uma situação diferente do momento de fala ser o ponto de referência para outra situação anterior ou posterior, saindo da concepção de referência dêitica para anafórica. Com base nesse movimento (dêitico - anafórico), o autor distingue os tempos absolutos (dêiticos: presente, passado e futuro) dos relativos (passado do passado, futuro do passado). Tempos verbais relativos têm o ponto de referência dado pelo contexto e podem ser representados por formas verbais não finitas e finitas. Uma forma não finita indicará um tempo relativo puro; já a forma finita indicará um tempo relativo-absoluto. Os tempos relativos puros, conforme Comrie (1990), têm como ponto de referência a forma finita mais próxima e podem receber a referência temporal (de passado, presente ou futuro) desse ponto. Se há uma combinação entre dois pontos de referência, o momento de fala e outro momento no tempo, a situação que toma esses dois pontos de referência é chamada de relativoabsoluta, pois sua interpretação temporal depende da existência de um ponto de referência antes ou depois do momento de fala e da localização da situação anterior, simultânea ou posteriormente a esse ponto. Vejamos como ficam os nossos dados a partir dessa acepção:

(01) Geralmente em quatro, cinco, né? Nunca sozinho, porque a gente ia pra longe, né? Ia pra $\varnothing$ tudo ao redor, né? E era difícil alguém que TIVESSE um carro naquela época. *Era mais ou menos isso. (SC CRI 03, p. 005)

Diagrama 11 - Expressão modo-temporal do PIS como passado cotemporal

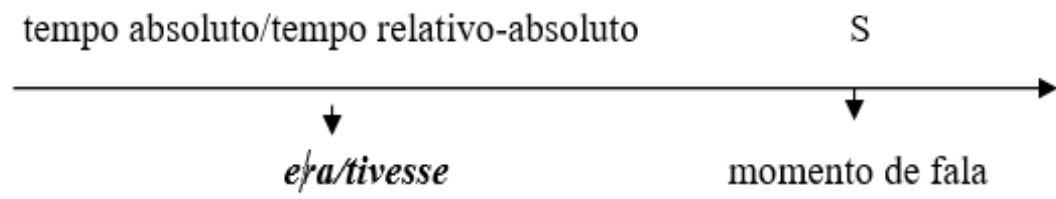

(02) Quando a gente, de vez em quando escutava, calcava o peso lá pra trá0s e (inint) acarcava e fazia aquela 0 quebraçada ("pra dizer") que nó0s 384azíamos uma taipa, que era obrigado a fazer uma taipa que ENCOSTASSE até no teto, uma taipa de pedra, [da]- da própria frente, né?* Então encostava até assim no teto, só deixava um corredor pelo meio, né? (SCCRI01, p. 5)

Diagrama 12 - Expressão modo-temporal do PIS como futuro do passado

tempos relativos tempo relativo-absoluto

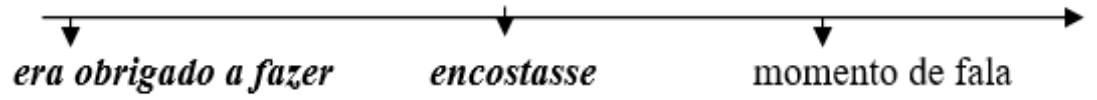

(03) Meu pai não queria que nós NAMORÁSSEMOS [...] (SCCRI01, p. 8) 
O terceiro dado que estamos considerando na amostra permite três interpretações: de cotemporalidade, como ocorre com o exemplo representado em 11; de posterioridade, como representamos em 12, e de anterioridade, conforme demonstramos abaixo.

Diagrama 13 - Expressão modo-temporal do PIS como passado do passado

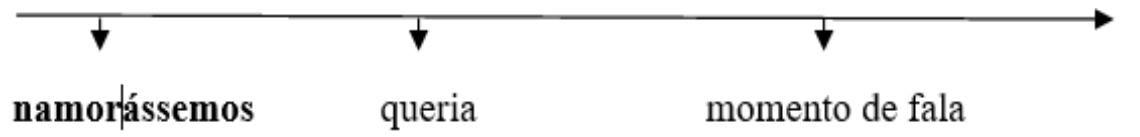

Em todas as representações, o imperfeito do subjuntivo ocorre como um tempo relativo-absoluto, tempo que tem um ponto de referência (era, era obrigado a fazer e queria) diferente do momento de fala. Dos nossos 350 dados, todos são de tempo relativoabsoluto. Embora a relação entre os tempos seja também lógico-temporal, a exemplo de Bello e Reichenbach, o diferencial aqui está no fato de se poder caracterizar um traço prototípico do imperfeito, o de expressar tempo relativo-absoluto. Esse traço pode desencadear variação, fazendo com que o imperfeito do indicativo ocorra em lugar do imperfeito do subjuntivo em situações cotemporais, como no exemplo citado por Domingos (2004, p. 92): "Eu pensei que ERA [FOSSE] eu, né que ele tinha me chamado e eu fui atrás dele..." (CRI 23, p. 39). A depreensão desse traço componente do imperfeito, apesar de auxiliar na explicação de processos de variação, ainda não resolve a interpretação de uma parcela de nossos dados (116), se a análise permanece em nível frasal. É por isso que trazemos, na próxima seção, a proposta de Rojo e Veiga (1999).

\section{A TEMPORALIDADE DO PRETÉRITO IMPERFEITO DO SUBJUNTIVO EM RELAÇÃO A SEU PONTO DE REFERÊNCIA: A PERSPECTIVA DE ROJO E VEIGA (1999)}

Rojo e Veiga (1999) elaboram uma teoria das relações temporais considerando as seguintes fórmulas: $(\mathrm{O})$ para origem, $(-\mathrm{V})$ para anterioridade, $(\mathrm{oV})$ para simultaneidade $\mathrm{e}$ $(+\mathrm{V})$ para posterioridade, como demonstramos no esquema abaixo:

Diagrama 14: Esquema representativo das relações temporais - sistema vetorial

\begin{tabular}{|c|c|c|}
\hline $\bar{A}$ & $\mathrm{~S}$ & $\bar{P}$ \\
\hline$(\mathrm{O}-\mathrm{V})$ & $(\mathrm{OoV})$ & $(\mathrm{O}+\mathrm{V})$ \\
\hline
\end{tabular}

Fonte: Adaptação de Rojo e Veiga (1999, p. 2877)

Os autores afirmam que o fato de termos relações mais complexas do que as apresentadas no esquema acima não justifica outras divisões, basta que se faça uso da combinação de vetores (V) para expressar as escalas, que são ilimitadas. Vejamos: 


\section{Quadro 3 - Representação das relações temporais complexas - sistema vetorial}

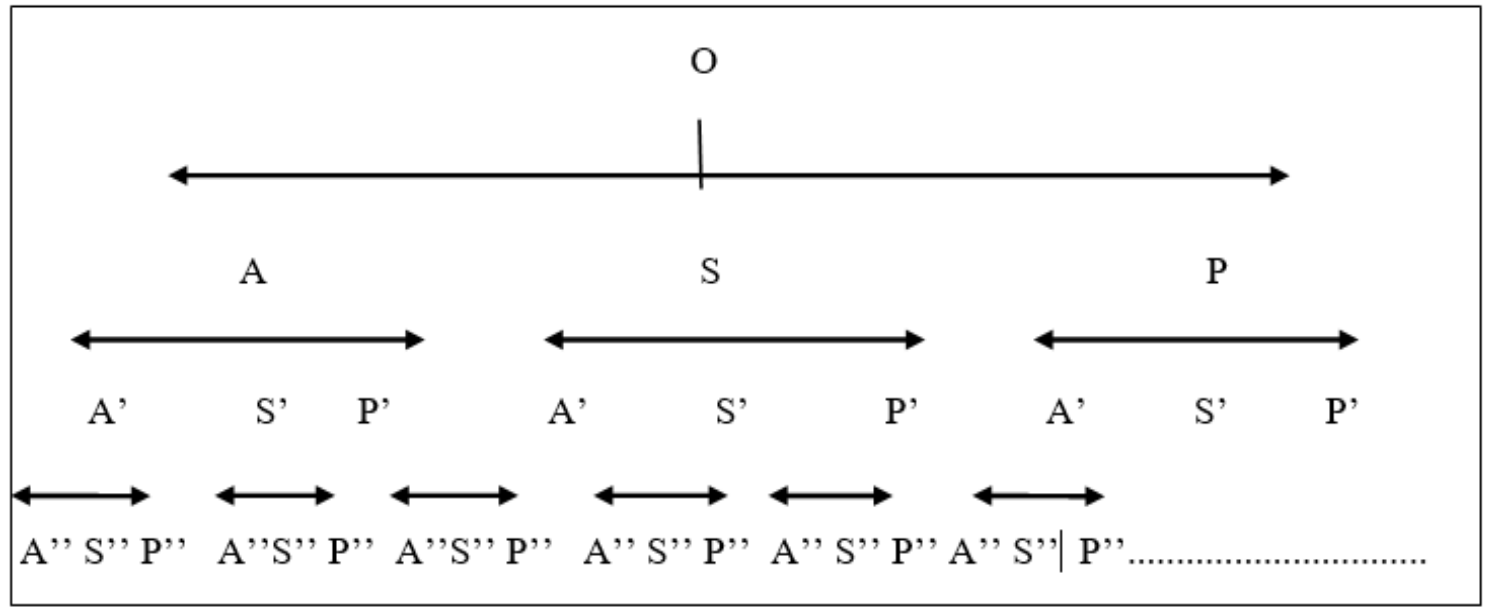

Fonte: Adaptação de Rojo e Veiga (1999, p. 2877).

O esquema ilustra, portanto, o ponto A como anterior, o ponto $\mathrm{S}$ como simultâneo e o ponto $\mathrm{P}$ como posterior à origem $(\mathrm{O})$, que, por sua vez, é o tempo de referência aos outros acontecimentos. Esses mesmos pontos podem, ainda, funcionar como referência a outras situações anteriores (A'), simultâneas ( $\left.\mathrm{S}^{\prime}\right)$ ou posteriores $\left(\mathrm{P}^{\prime}\right)^{8}$. Vislumbram-se, portanto, relações temporais como encadeamentos discursivos, não se limitando a compreender o tempo nos certames da estrutura frasal. Esse mecanismo garante a recursividade do sistema temporal de modo que o ponto $\mathrm{A}$, igual a $(\mathrm{O}-\mathrm{V})$, anterior, portanto, à origem, pode vir a ser o momento de referência para outras situações, sejam posteriores, simultâneas ou anteriores a ele, representadas respectivamente como $(\mathrm{O}-\mathrm{V})$ $\mathrm{V},(\mathrm{O}-\mathrm{V}) \mathrm{oV}$ e $(\mathrm{O}-\mathrm{V})+\mathrm{V}$. Rojo e Veiga (1999) categorizam o tempo verbal como dêitico, estabelecendo um sistema centrado em uma referência que se identifica, comumente, como momento de fala, a partir da qual se orientam as situações, de modo direto ou indireto, conforme ilustramos abaixo, considerando os mesmos dados anteriormente analisados.

(01) Geralmente em quatro, cinco, né? Nunca sozinho, porque a gente ia pra longe, né? Ia pra $\varnothing$ tudo ao redor, né? E era difícil alguém que TIVESSE um carro naquela época. *Era mais ou menos isso. (SC CRI 03, p. 005)

Diagrama 15 - Expressão modo-temporal do PIS como presente do passado - sistema vetorial

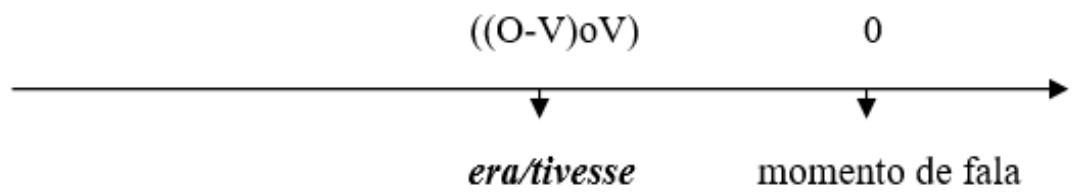

\footnotetext{
${ }^{8}$ As fórmulas devem ser lidas da esquerda para a direita. Uma fórmula como O-V refere-se a uma situação que é anterior (-V) à origem; já uma situação posterior à origem representa-se com $\mathrm{O}+\mathrm{V}$. Uma situação que retratasse o passado do passado seria representada por $(\mathrm{O}-\mathrm{V})-\mathrm{V}$.
} 
O diagrama 15 ilustra era e tivesse como passado em relação ao momento de fala $=(\mathrm{O}-\mathrm{V})$ e, no interior desse eixo, como sendo simultâneos $((\mathrm{O}-\mathrm{V}) \mathrm{OO})$. É possível observar a recursividade, mostrando que o tempo de referência é o momento de fala, tido como o ponto de origem $(\mathrm{O})$. Convém destacar que, nesse caso, o valor de $(\mathrm{O}-\mathrm{V}) \mathrm{OV}$ para tivesse também decorre da interpretação da expressão adverbial naquela época.

Considerando-se o contexto do dado (02), temos:

(02) Quando a gente, de vez em quando escutava, calcava o peso lá pra trá0s e (inint)

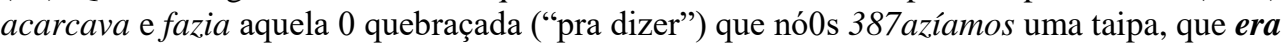
obrigado a fazer uma taipa que ENCOSTASSE até no teto, uma taipa de pedra, [da]- da própria frente, né?* Então encostava até assim no teto, só deixava um corredor pelo meio, né? (SCCRI01, p. 5)

Diagrama 16 - Expressão modo-temporal do PIS como futuro do passado - sistema vetorial

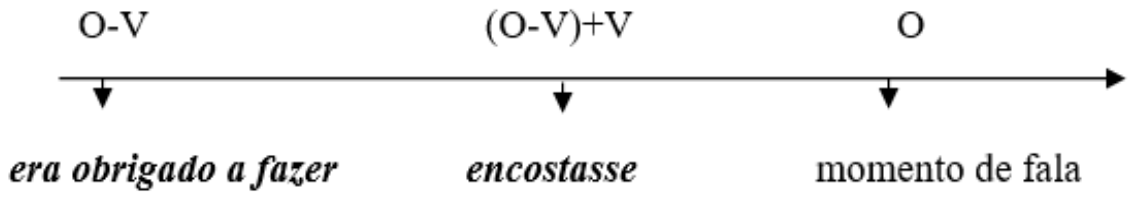

Nesse dado, há uma série de situações encadeadas - escutava, calcava, acarcava, fazia - que podem ser representadas, segundo fórmulas de Rogo e Veiga (1999), como simultâneas, no passado, ao processo de fazer a taipa: (((((O-V[escutava]) oV[calcava]) oV[acarcava]) oV[fazia])). Em análise vetorial, a ocorrência 02 fica assim configurada:

situações concomitantes a $\mathrm{S} 1$

era obrigado a fazer uma taipa..

que encostasse até no teto...
$((((\mathbf{O}-\mathrm{V}) \mathbf{o} \mathbf{V}) \mathbf{o V}) \mathbf{o V}))$

O-V

$(\mathbf{O}-\mathrm{V})+\mathrm{V}$

A postura teórica delineada por Rojo e Veiga (1999), pela recursividade, mostra-se apropriada para análise de sequências discursivas para além do contexto frasal, conforme propõe Freitag (2005). Embora seja evidente a lógica temporal decorrente da combinação dos vetores, Rojo e Veiga também analisam sequenciação temporal, não especificamente lógica temporal como fazem Reichenbach, Bello e Comrie.

Com relação à terceira evidência 'Meu pai não queria que nós NAMORÁSSEMOS', podemos calcular os vetores considerando as situações queria e namorássemos, a exemplo do que fizemos quando da análise nas perspectivas de Reichenbach, Comrie e Bello, mas considerando o contexto, porque o postulado teórico é recursivo e prevê situações temporais complexas que extrapolam o nível oracional, requerendo pontos de referência secundários a fim de não haver indeterminação temporal. A noção de PR, por conseguinte, é diferente: para quem opera com tempo, o PR funciona como funcionam as referências espaciais; para quem opera com tempo discursivo, o PR é o que garante sequenciação. Vejamos: 
(03) I* Meu pai não queria que nós namorássemos, que ele

$\mathrm{E}^{*}$ Ah ma0s a diferença não, eu não acho que

I* Ma0s só porque ele tinha jeito de ser mais velho, né? * E o pai não tinha nem cabelo branco (est) * Então o pai dizia: “* Esse aí tem idade pra ser teu pai, e não sei o que, e brigava, brigava, ma0s foi no fim, a gente namorou, uns oito meses eu acho, namoramos, casamos_

E* E estão até hoje!

I* É, no começo foi difícil, ma0s hoje está bem melhor, né? * Hoje nos entendemos mais.

Diagrama 17 - Expressão modo-temporal do PIS como futuro do passado - sistema vetorial

$\begin{array}{ccc}\downarrow & \downarrow & \downarrow \\ \mathrm{S} 1 & \mathrm{~S} 2 & \\ \text { queria } & \text { namorássemos } & \\ (\mathrm{O}-\mathrm{V}) & (\mathrm{O}-\mathrm{V})+\mathrm{V} & \\ & \text { namorou }(\mathrm{O}-\mathrm{V}) & \operatorname{casamos}((\mathrm{O}-\mathrm{V})+\mathrm{V})\end{array}$

Nesse dado, queria é anterior à origem (momento de fala) e funciona como ponto de referência para namorássemos, que também é anterior à origem, mas posterior a queria. Namorássemos, por sua vez, projeta uma contraparte factual (namorou), em estrutura adversativa, também anterior à origem. Segue-se casamos, anterior à origem, mas posterior a namorou. Esse encadeamento é o que garante a desambiguização. Do contrário, apenas com o primeiro trecho, a ambiguidade permaneceria, embora passível de análise lógica.

Considerando-se a amostra sob análise, verificamos que não se trata de apenas um dado cuja interpretação deva ocorrer em nível discursivo, mas de $116 \mathrm{em} 350$. Se enunciados assim são devidamente interpretados pelos usuários da língua, a interpretação da temporalidade deve advir da correlação entre mecanismos gramaticais e contextos discursivos, o que corrobora a tese de que tempo verbal é uma categoria discursiva. A aplicabilidade não somente ao exemplo (03), mas um conjunto maior de dados, conforme demonstramos neste artigo, permite-nos generalizações pautadas em interpretação estatística, conferindo à pesquisa, conforme Lass (1980), significância científica.

\section{CONSIDERAÇÕES FINAIS}

Sob as perspectivas de Bello (1841), Reichenbach (1947), Comrie (1990) e Rojo e Veiga (1999), analisamos a temporalidade do pretérito imperfeito do subjuntivo considerando-se seu ponto de referência. Essas propostas exibem semelhanças quanto à interpretação do ponto de referência: a) todas possuem o mesmo poder explanatório, como demonstramos no diagrama 18; b) oferecem recursos lógicos que possibilitam ler as fórmulas para depreender as temporalidades; e c) explicam como o tempo cronológico é representado pelo tempo gramatical. 
Diagrama 18 - Análise comparativa do ponto de referência nas propostas de Bello (1941), Reichenbach (1947), Comrie (1999) e Rojo e Veiga (1999)

\begin{tabular}{|ccc|}
\hline $\mathrm{O}-\mathrm{V}$ & $(\mathrm{O}-\mathrm{V})+\mathrm{V}$ & $\mathrm{O} \rightarrow$ Rojo e Veiga \\
$\mathrm{A}$ & $\mathrm{PA}$ & $\mathrm{C} \rightarrow$ Bello \\
$\mathrm{PR}$ & $\mathrm{PE}$ & $\mathrm{PS} \rightarrow$ Reichenbach/ \\
Tempo absoluto & tempo relativo-absoluto & momento de fala $\rightarrow$ Comrie \\
\hline$\downarrow$ & & \\
efa obrigado a fazer & encostasse & momento de fala \\
\hline
\end{tabular}

As diferenças entre as propostas residem em: manifestação lógica da temporalidade e orientação anafórica por Bello, Reichenbach e Comrie versus visão de temporalidade centrada no tempo e no discurso e orientação dêitica por Rojo e Veiga. Além disso, Bello, Comrie e Reichenbach expõem nove possibilidades de representação temporal, mas Bello sugere interpretações secundárias e metafóricas, dando licença a interpretações que façam uso recursivo das fórmulas; em Rojo e Veiga, observa-se, pelo menos teoricamente, que as possibilidades de representação temporal são ilimitadas. Em relação à ambiguidade, constatada no dado (03), somente é resolvida quando aplicada a proposta de Rojo e Veiga (1999), em virtude de considerar sequenciação discursiva em relação ao momento de fala para desfazer ambiguidades.

No decorrer do texto, além dos construtos teóricos, mostramos aplicação a dados, os quais foram, ainda, quantificados, para que as interpretações mais recorrentes do imperfeito do subjuntivo em português viessem à tona. Embora nossa condução analítica induza à escolha de propostas recursivas e discursivas para a interpretação do imperfeito do subjuntivo, não foi nossa pretensão descaracterizar as demais, devido à relevância histórica e à possibilidade de aplicação à maioria dos dados. Análises de outros tempos verbais também têm mostrado a necessidade de ampliação contextual para a correta interpretação dos enunciados. A título de ilustração, podemos considerar a pesquisa de Coan (2003), sobre o pretérito mais-que-perfeito, também um tempo relativo-absoluto. A autora mostra que a análise do ponto de referência deve ultrapassar os limites estruturais e atuar, também, nas dimensões semântica e pragmática, pois os pontos de referência nem sempre são verbos ou advérbios; podem, sim, ser temporais, mas há os discursivos, os pressupostos e os pragmáticos. 
BACK, A. C. Di P. A multifuncionalidade da forma verbal-sse no domínio Tempo-Aspecto-Modalidade: uma abordagem sincrônica. 2008. 310f. Tese (Doutorado em Linguística) - Programa de Pós-graduação em Linguística, Universidade Federal de Santa Catarina, Florianópolis, 2008.

BELLO, A. Gramática de la lengua castellana destinada al uso de los americanos. Madrid:EDAF, [1847] 1984.

Análisis ideológica de los tiempos de la conjugación castellana. In: Obra literaria. Caracas: Ayacucho, [1841] 1979. p. 415-459.

BYBEE, J.; PERKINS, R.; PAGLIUCA, W. The Evolution of Grammar: Tense, Aspect, and Modality in the languages of the world. Chicago-USA: 1994.

COAN, M. As categorias Tempo, Aspecto, Modalidade e Referência na significação dos pretéritos maisque-perfeito e perfeito: correlação entre função(ões)-forma(s) em tempo real e aparente. 2003. 238f. Tese (Doutorado em Linguística) - Programa de Pós-graduação em Linguística, Universidade Federal de Santa Catarina, 2003.

COMRIE, B. Tense. 4. ed. Cambridge University Press, ([1985] 1990.

CORÔA, M. L. M. S. O tempo nos verbos do português: uma introdução à sua interpretação semântica. 2. ed. São Paulo: Parábola Editorial, 2005.

DOMINGOS, R. Variação no uso do pretérito imperfeito (indicativo e subjuntivo) na função de cotemporalidade a um ponto de referência passado. 2004. Dissertação (Mestrado em Linguística) Programa de Pós-graduação em Linguística, Universidade Federal de Santa Catarina, Florianópolis, 2004. FREITAG, R. M. Ko. Tempo na frase e tempo no texto: as teorias de Reichenbach e de Rojo e Veiga. Linguagem em (Dis)curso, Tubarão, v. 5, n. 2, p. 389-413, jan./jun. 2005.

GIVÓN, T. On Understanding Grammar. New York: Academic Press, 1979.

HEINE, B.; HÜNNEMEYER, F. From Cognition to Grammar: Evidence from African Languages. In: TRAUGOTT, E. C.; HEINE, B. Approaches to grammaticalization. Amsterdam/Philadelphia: John Benjamins Publishing Co, 1991.

LASS, R. On explaining language change. New York: Cambridge, 1980.

LYONS, J. Semantics. Cambridge: Cambridge University Press, 1977.

NEVES, M. H. M. A modalidade. In: KOCH, I. G. V. (Org.). Gramática do Português Falado 6:

Desenvolvimentos. Campinas: Editora da UNICAMP/FAPESP, 1996. p. 163-200.

REICHENBACH, H. Elements of Symbolic Logic. New York: Macmillan Company, 1947.

ROJO, G.; VEIGA, A. El tiempo verbal: Los tiempos simples. In: Ignácio Bosque y Violeta Demonte (Eds.). Gramática descriptiva de la lengua española. Madrid: RAE-Espasa Calpe, 1999. Cap. 44.

\section{ANEXO - SÍMBOLOS UTILIZADOS NA TRANSCRIÇÃO DAS OCORRÊNCIAS}

E

I

*

(est.)

$\varnothing[\mathrm{ma} 0 \mathrm{~s}]$

(inint.)

[ ]
Entrevistador

Informante

Início de turno

Estímulo

Inserção de segmentos na transcrição fonológica

Ininteligível

Repetição

BACK, Angela Cristina Di Palma; COAN, Márluce. A temporalidade do pretérito imperfeito do subjuntivo em relação a seu ponto de referência: perspectivas teóricas. Linguagem em (Dis)curso - LemD, Tubarão, SC, v. 18, n. 2, p. 375-391, maio/ago. 2018. 
Recebido em: 29/08/17. Aprovado em: 05/05/18.

Title: The temporality of the imperfect past tense of the subjunctive in relation to its point of reference: theoretical perspectives

Authors: Angela Cristina Di Palma Back; Márluce Coan

Abstract: In this paper, the perspectives by Bello (1841), Reichenbach (1947), Comrie (1990) and Rojo and Veiga (1999) on the reference point are applied to 350 data of subjunctive imperfect from 60 sociolinguistic interviews present in the Sociolinguistic Atlas of the AMREC region. The proposal is to: demonstrate to what extent these perspectives approach or distance themselves; empirically prove the application of the proposals, through qualitative-quantitative analysis; attest that time is a discursive category. Thereunto, similarities are observed in terms of explanatory power, logical resources and correlation between time and tense. The main difference resides in the vision of temporality: logical or discursive ones. Regarding to the data, 116 smples are ambiguous, if we consider Bello (1841), Reichenbach (1947) and Comrie (1990) proposals. By Rojo and Veiga (1999) proposal, because it is recursive and goes beyond sentence, it dissolves ambiguity and these data are analyzed discursively as previous or posterior or co-temporal to the reference point.

Keywords: Grammatical tense. Discursive tense. Ambiguity. Co-temporality.

Título: Temporalidad del pretérito imperfecto del subjuntivo en relación con su punto de referencia: perspectivas teóricas

Autores: Angela Cristina Di Palma Back; Márluce Coan

Resumen: En este artículo, las perspectivas de Bello (1841), Reichenbach (1947), Comrie (1990) y Rojo y Veiga (1999) sobre punto de referencia son aplicadas a 350 datos de pretérito imperfecto del subjuntivo provenientes de 60 entrevistas socio-lingüísticas del Atlas Socio-lingüístico de la región de AMREC. El propósito es: demostrar en qué medida tales perspectivas se aproximan o se alejan; comprobar empíricamente la aplicación de las propuestas, por medio del análisis cualitativo-cuantitativo; y atestar que tiempo es una categoría discursiva. Para ello, observa semejanzas acerca: del poder explicativo; y de recursos lógicos y correlación entre tiempo cronológico y gramatical. La principal diferencia es en la visión da temporalidad: lógica o discursiva. Cuanto a los datos, 116 de ellos son ambiguos, en la perspectiva lógica de Bello (1841), Reichenbach (1947) y Comrie (1990). En la propuesta de Rojo y Veiga (1999), por ser recursiva y ultrapasar los límites de la frase, la ambigüedad se deshaz: los datos son discursivamente interpretados como anteriores o posteriores o co-temporales al punto de referencia.

Palabras clave: Tiempo gramatical. Tiempo discursivo. Ambigüedad. Co-temporalidad.

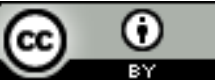

Este texto está licenciado com uma Licença Creative Commons Atribuição 4.0 Internacional.

BACK, Angela Cristina Di Palma; COAN, Márluce. A temporalidade do pretérito imperfeito do subjuntivo em relação a seu ponto de referência: perspectivas teóricas. Linguagem em (Dis)curso - LemD, Tubarão, SC, v. 18, n. 2, p. 375-391, maio/ago. 2018. 